\title{
“Exercise as the Human Body’s Conductor” or the Significance of Exercise in Early Childhood
}

\author{
Baloghné Bakk Adrienn \\ University of Sopron, Sopron, Hungary

\begin{abstract}
The focus of our topic is doing regularly physical exercises, regarding healthy way of life, which is also the basis of development of kindergarten aged children. The children of consecutive generations are growing fat and the number of overweight children in the generation change has increased. Although not all fat children will become fat adults, but this is very likely. Prevention should be started as early as the age of preschool. Physical activity must play an outstanding role in ensuring healthy development of children's organisms.
\end{abstract} \\ Keywords: early childhood, kindergarten, obesitas, physical exercises (PE)
}

According to WHO (2014) data, it is worrying that the number of fat or overweight children worldwide under the age of five is 41 million, which is estimated to grow to 70 million by 2025! According to statistics, 22 million overweight and five million fat children live in European Union countries; in addition, this number increases by 300,000 every year. In Hungary, the ration of overweight and fat children has doubled in 10 years and the country has joined the leading group in this respect.

Baloghné Bakk Adrienn, Ph.D., Dr., associate professor, Art and Sport Department, Benedek Elek Faculty of Pedagogy, University of Sopron, Sopron, Hungary. 

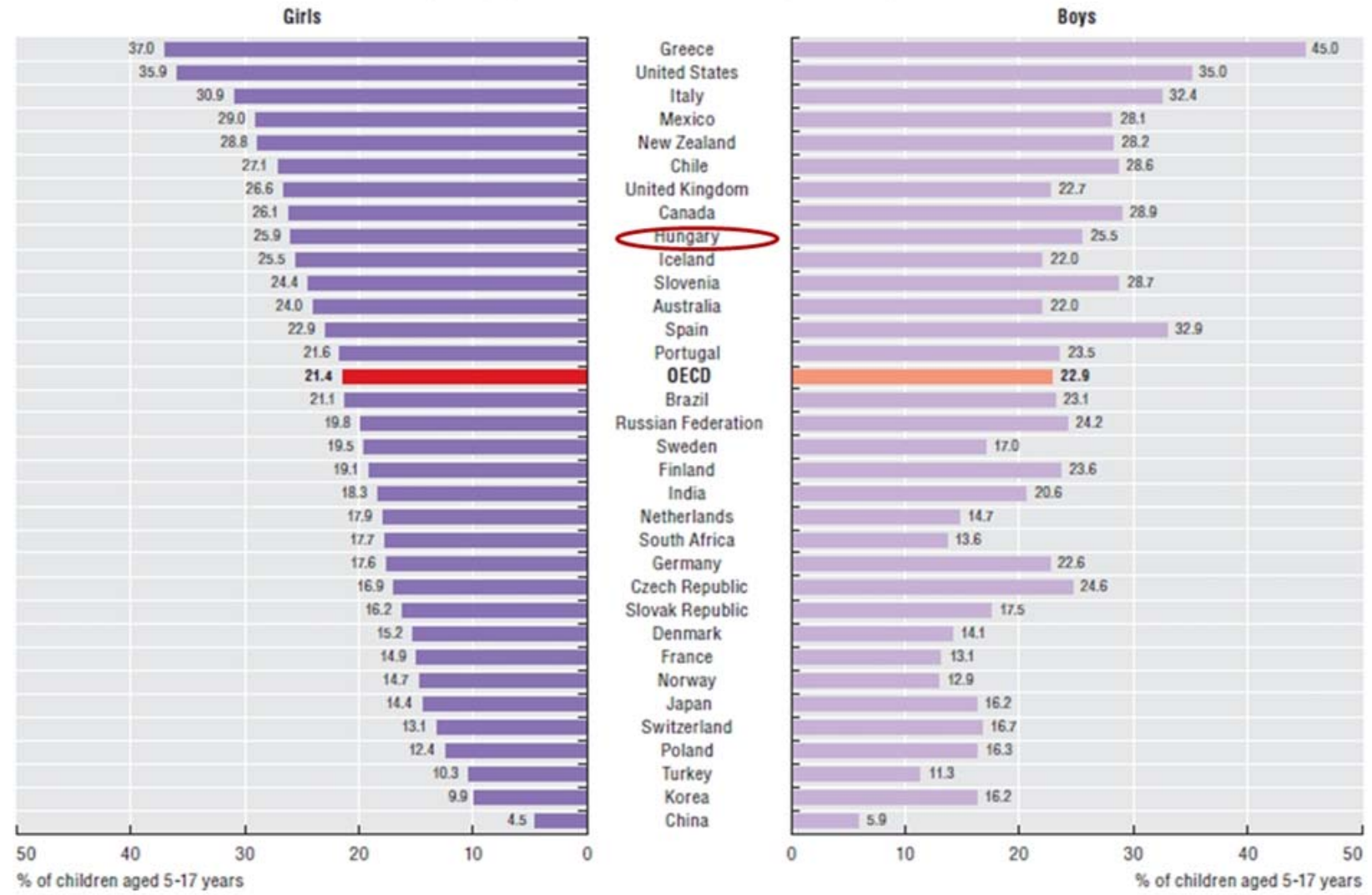

Figure 1. Source: OECD Health Data, 2011.

Obesity has been declared by the WHO as a disease, even as one of the 10 most serious diseases. All this can increase your risk of early death by up-to $44-88 \%$.

Obesity is a disorder of metabolism, happening as a genetic, central nervous system or endocrine and environmental impact, which causes a balance modification in the energy balance. This process is manifested in increased food intake and decreased energy output, then causes increased fat storage.

The reasons for all are:

- excessive food energy consumption, bad nutrition habits;

- lack of physical exercises, sedentary way of life;

- genetic predisposition, inheritance;

- endocrine disorders, metabolic disorders;

- organ disorders;

- side effects of medicines

- psychiatric disorders.

The further seriousness of this problem is that this disease has many complications.

- cardiovascular diseases;

- diabetes;

- hypertension;

- internal medical problems (e.g., liver and kidney failure); 
- locomotor disorders (e.g., spinal deformity, X leg, foot pad);

- dermatological problems;

- infertility;

- malignant tumors.

It can be observed that the lives of kindergarten children are narrowed in a sense. The possibility of experiencing natural freedom of movement has diminished, and inactivity is already present at this age also.

In our opinion, in the kindergarten educational programs, the education of healthy lifestyle should have a more cardinal role, as well as it should meet the children's age related demand for movement. The role of physical education must be more and more important.

In the framework of institutional education, kindergarten physical education provides the most opportunities, the quality and quantity of which can determine the healthy development of children for a long time.

The most important tasks of the activities, involving movements, are to meet the need of children to move and develop their habit of doing regular physical exercises.

The application of regular motion has a beneficial effect on conditional skills, especially on the development of strength and stamina, which influence the capacity of the child's body, healthy development. They play an important role in the development of muscle balance, necessary for proper posture, enhance the effect of education, regarding healthy lifestyle, and may prevent overweight. Kindergarten physical education contributes to the desired results by providing versatile movement experiences.

Physical exercise is also incorporated into other activities of kindergarten life, while interacting with the development of the children's personalities, positive self-images, self-control, emotion control, compassionate behavior, rule following collaboration, communication, problem solving thinking (national core-program of kindergarten education).

Educational principles of physical education are: playfulness, activity, experience, differentiated development, complexity, the principle of ensuring freedom of the child, as well as the principle of spontaneity and directivity (Kovács György-Bakosi, 2004).

\section{Micro Research}

The aim of our study is to see clearly the situation of kindergarten physical education in the larger cities of Hungary.

The most important thing is to determine how well the methodological knowledge of kindergarten physical education can be realized in practical (kindergarten) life and how emphasized it is in kindergarten education.

The following questions were raised in connection with the investigation and we were looking for answers:

1. What are the facility conditions in kindergartens? I.e., whether the kindergartens have gymnasiums, courts of appropriate sizes, where they can do physical education sessions?

2. Weekly, how regularly and how many minutes of physical education activities are held?

3. What is the nature of physical education activities? Are they done spontaneously or in an organized way?

4. Which tools are preferred by kindergarten teachers in the field of physical education?

5. What proportion of obese or overweight children in kindergarten prevails according to the kindergarten teacher's judgment? 
6. How many kindergarten teachers work, and in what groups?

To answer our questions, we selected document analysis and written inquiry from among the methods of pedagogical research. We asked the kindergarten teachers in Hungary in 14 accidentally selected cities in kindergartens (N192).

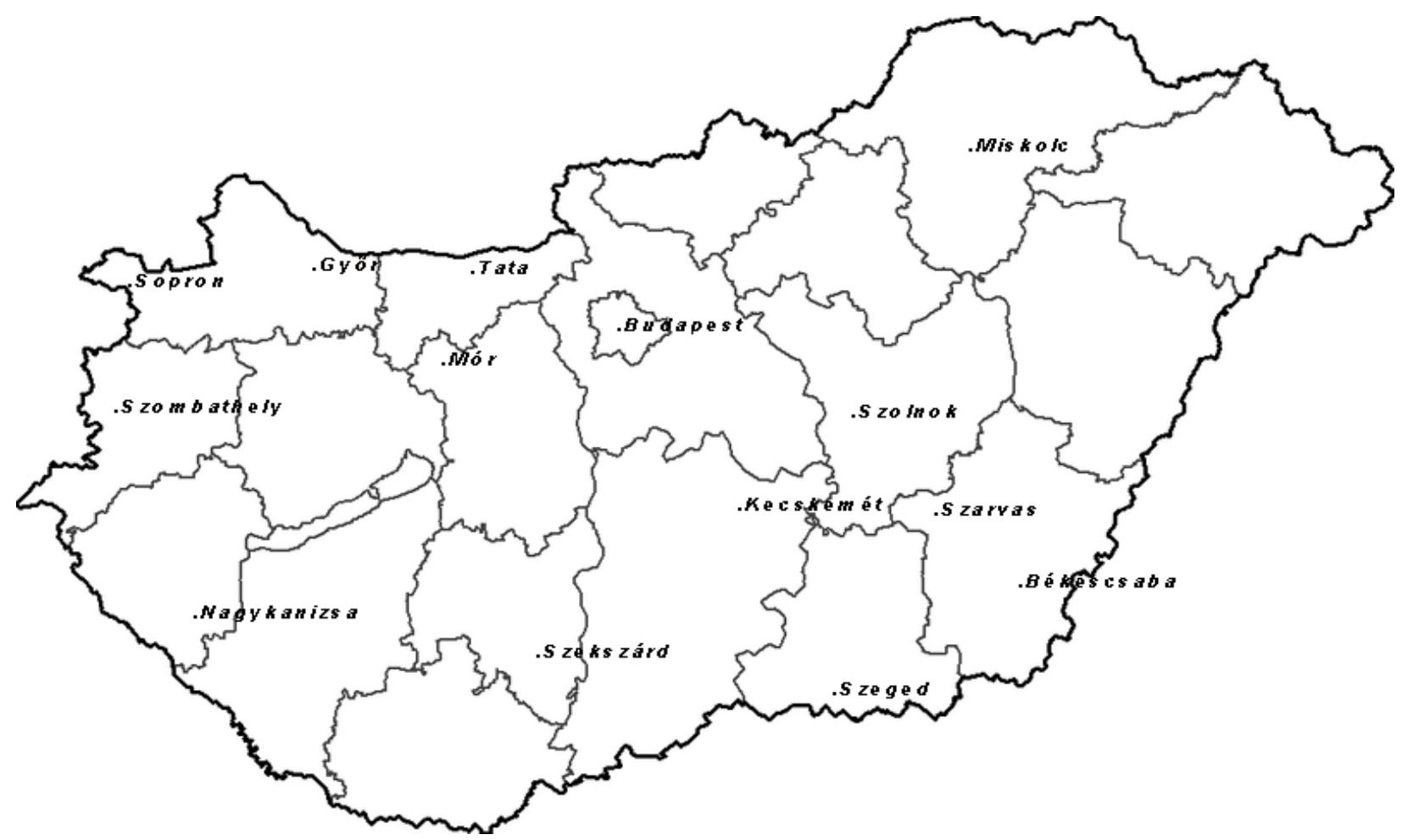

Figure 2. Hungary’s kindergarten.

\section{Results}

The surveyed kindergarten teachers are all women; 39\% have been in the field for more than 25 years. 11\% of them are for $20-25$ years; $13 \%$ are for $15-20$ years, who have a lot of experience. A further $14 \%$ are for $10-15$ years; $8 \%$ for $5-10$ years have been working in this field. The remaining $15 \%$ can be considered as entrants, because they have been working as kindergarten teachers for less than five years.

Based on the examined sample, we found that only $29 \%$ of kindergartens have gymnasiums, and $24 \%$ have classroom, i.e., an unused group room was set up for a gymnasium (which is much smaller than necessary), where physical education is held. So, half of the surveyed kindergartens do not have a separated room (gymnasium), where they could organize activities, involving motion, or to meet the needs of children, regarding motion. Based on the data, in this institutions kindergartens are overloaded, the teachers work in groups (27-31 people/group) where the number of children is high and they work with almost $100 \%$ space utilization, where first of all children of mixed age (3-7 years) are present. Teachers say that there are on average 7-8 overweight children in their groups.

The surveyed kindergarten teachers hold only once a week planned and organized physical education for children, but with very different time zones and time periods. There is no consensus among teachers about time, 
but sport specialists recommend more do physical exercises in the mornings, and approximately 30 minutes of time. The other activities, involving movements, are completely spontaneous, not well structured, not conscious, not planned and they often neglected, in the worst cases they are not carried out at all.

It is a difficult task to offer day-to-day planned moving tasks to children, but the present age induces this need, by which the inactivity and related diseases can be prevented. According to our observation, in the complexity of the educational areas, kindergarten activities, involving movements, have not been successfully included in kindergarten education programs. An important point is that every day, there should be controlled movement activities in kindergartens, in accordance with age and group composition.

The survey showed that teachers use only four or five devices (ball, beanbag, hoop, school desk, ribbon) in motion activities. These tools are not enough. Teachers are insecure, regarding the application of less used or less popular tools, and therefore they do not use them.

\section{Conclusion}

In the lives of today's children, movement activities should play a more important role, regarding kindergarten education. From the point of view of movement development, the infant age is the most important milestone, because if we do not improve motor and coordination skills and capacities, the lag is unbeatable. If children get used to and love physical exercises, they will later be required and become an integral part of their personalities. They also establish the good state of health in the adulthood.

The promotion of regular physical exercises and the development of healthy and conscious eating habits are the most important tools for improving the physical and mental health of Hungarian children and to prevent overweight (Csányi, 2011).

It is a goal and a task to prefer more regular and more demanding activities in kindergartens. There must be ensured as many opportunities for day-to-day activities, involving movement, as possible, must be created the necessary material conditions: building of gymnasiums, ensuring the widest range of sports equipment.

In the field of kindergarten education, a more uniform system of standards, methodology, differentiation, and time content should be established at national level.

\section{References}

Adrienn, B. B. (2015). A survey on everyday physical education in kindergartens of Sopron and it’s region. Trainig and Practice, 13(1-2), 161-168.

Ágnes, N. (2012). How fat is the hungarian children?. Retrieved 2018-08-12 from http://www.origo.hu/egeszseg/20121031-mennyire-kover-a-magyar-gyermek.html

Csányi, T. (2011). Physical education in Kindergarten and schools in the 21th century II. Countrywide school opening Conference Gellért Hotel, Budapest, VIII. 24.

Kovács György-Bakosi, É. (2004). Pedagogy of kindergarten I. Physical education.

Magdolna, R. (2008). The fatness and his accompanying diseases. Kairosz Publishing. Retrieved 2018.08 .12 from http://www.ilosvay.net/images/Vendegek/DrRodekonyv.pdf

$\begin{array}{lllll}\text { OECD Health } & \text { Data. } & \text { (2011). Retrieved from }\end{array}$ https://www.google.hu/search?q=OECD+Health+Data+2011\&rlz=1C1GGGE_huHU556HU571\&source=lnms\&tbm=isch\&s a=X\&ved=0ahUKEwjSvormk_vcAhVEJpoKHV4qCNUQ_AUICigB\&biw=1920\&bih=974\#imgrc=pAhOYSjPyFYL8M 